\title{
O potencial de Bituruna para o enoturismo, no Estado do Paraná, Brasil
}

\section{The Bituruna potential for wine tourism in the State of Paraná, Brazil}

\author{
Leticia Bartoszeck Nitsche (NITSCHE, L. B.) ${ }^{*}$ \\ Luciane de Fátima Neri (NERI, L. de F.) ${ }^{* *}$ e \\ Zulméia Ferreira Pinheiro (PINHEIRO, Z. F.) ${ }^{* * *}$
}

\begin{abstract}
RESUMO - Diante do desenvolvimento de zonas enoturísticas no território brasileiro, o presente artigo tem por objetivo analisar o potencial para o desenvolvimento do enoturismo em Bituruna, município localizado no Estado do Paraná, na Região Sul do Brasil. A pesquisa se caracteriza como qualitativa do tipo exploratória, realizada por meio da análise de referenciais bibliográficos, documentais e entrevistas com os principais produtores de vinho do município, além de participação em grupo de trabalho com empresários locais. Os resultados forneceram uma visão panorâmica sobre o potencial enoturístico, de acordo com as informações sobre os equipamentos e serviços turísticos do município e a produção de vinho nas propriedades rurais, tais como: ano de inicio da atividade, quantidade produzida, processos de produção, aprimoramento da qualidade do produto, formas de comercialização, participação em organizações coletivas, inserção no desenvolvimento turístico local e cultura étnica como atrativo.
\end{abstract}

Palavras-chave: Bituruna; Enoturismo; Vinícolas; Cultura étnica.

ABSTRACT - Before the development of wine tourism areas in Brazil, this article aims to analyze the potential to develop wine tourism in Bituruna, cityy located in the state of Paraná, in southern Brazil. The research is characterized as qualitative with exploratory type, performed through bibliographical and documentary analyses and interviews with the main wine producers in the city, as well as the participation in the work group with

\footnotetext{
Formação: Graduação em Turismo (Bacharelado); Especialização em Planejamento e Gestão do Turismo; Mestrado e Doutorado em Geografia, títulos obtidos na Universidade Federal do Paraná (UFPR). Atividade profissional: Professora do Curso de Graduação em Turismo e do Mestrado em Turismo da UFPR; Coordenadora do projeto Turismo e desenvolvimento rural no Brasil. Endereço: Rua Dr. Faivre, 405, Ed. D. Pedro II, $3^{\circ}$ andar. CEP: 80060-140 - Curitiba - Paraná (Brasil). Telefone para contato: 41 33605050. E-mail: 1ticia@gmail.com

*** Formação: Graduação em Turismo (Bacharelado) e Especialização em Análise Ambiental, ambos pela UFPR; Master em Gestão Púbica do Turismo: competitividade e sustentabilidade pela Universidade Internacional de Andaluzia - UNIARA (Espanha) e Doutorado em Turismo pela Universidade de Málaga (Espanha). Atividade profissional: Professora do Curso de Graduação em Turismo da UFPR. Endereço: Rua Dr. Faivre, 405, Ed. D. Pedro II, $3^{\circ}$ andar. CEP: 80060-140 - Curitiba - Paraná (Brasil). Telefone para contato: 41 33605050. E-mail: luciane@ufpr.br

*** Formação: Graduação em Turismo (Bacharelado) pela UFPR e Graduação em Direito (Bacharelado) pela Pontifícia Universidade Católica do Paraná (PUC-PR) e Master em Gestão Púbica do Turismo: competitividade e sustentabilidade pela Universidade de Andaluzia (Espanha). Atividade profissional: Professora do Curso de Turismo das instituições: PUC, TUIUTI, FACINTER, OPET, UNICENP; Consultora de Planejamento e Desenvolvimento Setorial do Serviço Brasileiro de Apoio às Micro e Pequenas Empresas - SEBRAE-PR; Sócia da Superagui Planejamento Turístico; Consultora para Programas de Uso Público em Unidades de Conservação. Endereço: Rua Dr. Faivre, 405, Ed. D. Pedro II, $3^{\circ}$ andar. CEP: 80060-140. Curitiba - Paraná (Brasil). Telefone para contato: 41 33605050. E-mail: zulpinheiro@yahoo.com.br
} 
entrepreneurs. The results provided an overview on the wine tourism potential, according to information on tourist facilities and services of Bituruna and wine production on the farms, such as: the year of the activity beginning, quantity produced, production processes, improving product quality, marketing, participation in collective organizations, inclusion in the local tourism development and ethnic culture as attractive.

Key words: Bituruna; Wine tourism; Wineries; Ethnic culture. 


\section{INTRODUÇÃO}

A enocultura como atrativo turístico vem se destacando em estudos realizados na Austrália, Nova Zelândia, Canadá e Estados Unidos (MITCHELL; HALL, 2006). Pesquisas mostram que a experiência do enoturista vai além do conhecimento sobre o vinho e o seu processo de produção (HALL, 2004), pois ele interage com outros aspectos agregados ao cenário do vinho, como a paisagem, a cultura local, a arquitetura, a gastronomia, as festas típicas das localidades, entre outros aspectos inerentes a um lugar.

O Brasil vem aprimorando o desenvolvimento da vitivinicultura que ganha variados contornos ao se adaptar aos diferentes biomas do seu vasto território e ao fato de ser manipulada por grupos culturais distintos como os oriundos das etnias que colonizaram o Brasil (FLORES, 2012).

Tais aspectos estão em consonância com as colocações de Zanini e Rocha (2010) sobre o estudo comparativo entre as regiões vinícolas do Vale dos Vinhedos (Rio Grande do Sul/RS) e Vale do São Francisco (Bahia/BA/Pernambuco/PE) em que a “diversidade de culturas, de paisagens e de histórias que caracterizam o Brasil deve estampar a imagem dos destinos enoturísticos, vinculando o vinho aos traços próprios de cada uma das regiões" (ZANINI; ROCHA, 2010, p. 87).

A geração de tais cenários se constitui em um rico potencial para o turismo, como é possível comprovar nos diagnósticos sobre o enoturismo brasileiro publicados pelo Serviço Brasileiro de Apoio às Micro e Pequenas Empresas - SEBRAE e Instituto Brasileiro do Vinho - IBRAVIN (FLORES, 2011; 2012).

Em relação ao Sul do país pode-se afirmar que o enoturismo é uma atividade consolidada no Estado do Rio Grande do Sul com 6 zonas de interesse enoturístico, como a Serra Gaúcha onde se destaca a rota do Vale dos Vinhedos. (FLORES, 2012, p. 28-31). Em Santa Catarina são 4 zonas de interesse enoturístico com diferenciais como o cultivo de vinhedos de altitude conjugado a belas paisagens. (FLORES, 2012, p. 6568). Segundo a mesma autora no Paraná são 8 zonas de interesse enoturístico (Figura 1), sendo as zonas: Campo Largo, Santa Felicidade, Colombo, Piraquara e Região Metropolitana formadas por municípios próximos a Curitiba, onde Nitsche (2014) identificou pelo menos 17 vinícolas que se enquadram como propriedades de turismo 
rural, principalmente administradas por agricultores familiares. Além destas, cita-se também as zonas de Toledo e Norte com propriedades vinícolas que desenvolvem o turismo rural.

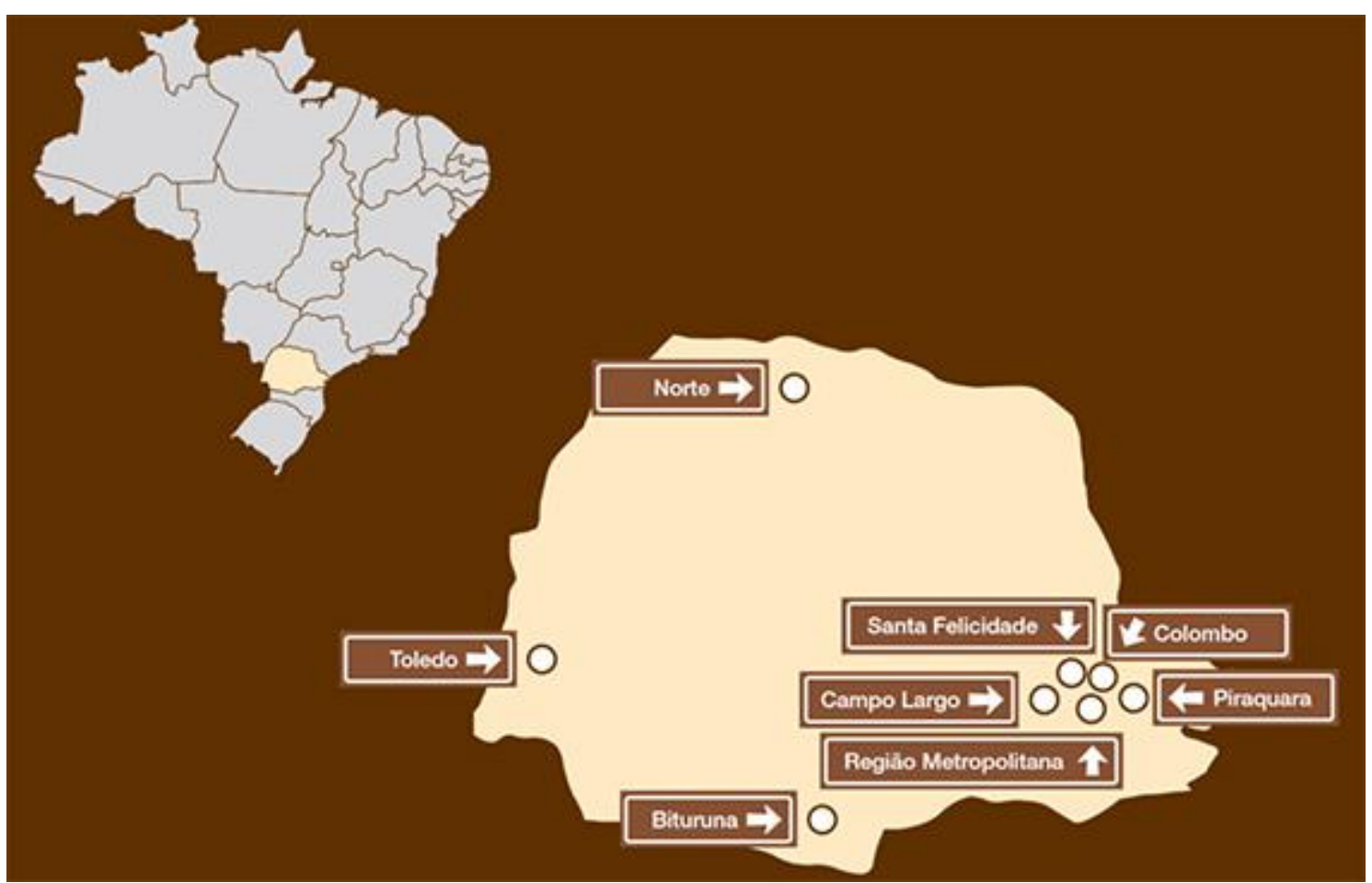

FIGURA 1 - MAPA DAS ZONAS ENOTURÍSTICAS DO ESTADO DO PARANÁ, BRASIL. FONTE: Flores, 2012, p. 79.

Dentre as zonas enoturísticas paranaenses destaca-se a do município de Bituruna, foco da presente pesquisa. O município colonizado por imigrantes italianos, alemães, ucranianos, libaneses e poloneses que se fixaram na Região do Centro Sul do Paraná, localiza-se a 317 km de Curitiba e possui aproximadamente 16 mil habitantes. (BITURUNA, 2013). Tem sua economia baseada na extração e beneficiamento da madeira, na indústria têxtil, na produção e beneficiamento de erva mate e na produção e comércio de vinhos e cachaça. (BITURUNA, 2013). A produção de uva de Bituruna ocupa 134 ha de área colhida (IBGE, 2012). São pelo menos 10 vinícolas responsáveis pela produção artesanal de suco de uva e de mais de 500 mil litros de vinho de mesa por ano (FLORES, 2011).

Nas décadas de 1960 e 1970 a vitivinicultura era uma das grandes promessas da economia da região, ocasião em que se criou uma exposição vinícola em Bituruna e mais tarde a Festa da Uva, realizada em plena safra para comercialização de uvas e 
derivados advindos dos agricultores da região, sendo este um dos principais eventos regionais. (BITURUNA, 2013)

Turisticamente, o município faz parte da Região Turística Terra dos Pinheirais que compreende 19 municípios do Centro Sul do estado do Paraná e também compõe a Associação dos Municípios Sul Paranaense (AMSULPAR) juntamente a outros oito municípios. (TERRA DOS PINHEIRAIS, 2013).

Diante da importância que a vitivinicultura representa para o município, este estudo tem por objetivo analisar o potencial para o desenvolvimento do enoturismo em Bituruna.

A pesquisa se caracteriza como qualitativa, do tipo exploratória por meio da análise de diagnósticos sobre o enoturismo de Bituruna (FLORES, 2011, 2012), bem como de outros documentos e referenciais bibliográficos, além de entrevista com dois dos principais produtores locais, levada a efeito em setembro de 2013. Os dados coletados também se consolidaram pela participação de uma das autoras na condução de um grupo de trabalho com empresários locais promovido pelo SEBRAE/PR durante os anos de 2010 e 2011, gerando fundamentação de conhecimentos específicos sobre o potencial turístico aliado a produção de vinhos.

Os dados obtidos trouxeram informações sobre a produção de vinho nas propriedades rurais, tais como: ano de início da atividade, quantidade produzida, processos de produção, aprimoramento da qualidade do produto, formas de comercialização, participação em organizações coletivas, inserção no desenvolvimento turístico local, entre outros.

\section{O POTENCIAL DE BITURUNA PARA O ENOTURISMO}

Dentre as 10 vinícolas existentes no município, duas se destacam pela localização próxima ao centro da cidade e pelo trabalho desenvolvido em busca do aprimoramento dos seus produtos (FLORES, 2011). As vinícolas podem ser classificadas como de pequeno e de médio porte com uma produção anual variando de 3 mil a 83 mil litros de vinhos finos, de mesa e sucos (BITURUNA, 2013), sendo o principal público alvo as classes B e C (FLORES, 2011). 
Quanto à disponibilidade de equipamentos turísticos, a cidade dispõe de 42 estabelecimentos de alimentos e bebidas e dois hotéis que totalizam 101 leitos (SOUZA, 2008). No que se refere às vias de acesso às vinícolas, a sua maioria é composta por estradas de chão e se faz necessária a melhoria da sinalização de aproximação e de identificação dos estabelecimentos. (FLORES, 2011).

O estilo arquitetônico das vinícolas é simples, com jardins bem cuidados e em harmonia com a paisagem rural; não há profissionais com formação em turismo atuando nos locais; são os membros das próprias famílias que atuam no atendimento aos visitantes. Para melhorar este quesito os produtores têm participado de treinamentos oferecidos pelo SEBRAE, pelo Serviço Nacional de Aprendizagem Rural - SENAR, ou pela Prefeitura Municipal. (FLORES, 2011). Não existem dados oficiais do fluxo turístico no município, mas estima-se que aproximadamente 50 mil pessoas visitem as vinícolas para comprar vinho. Estes vêm em família, de carro próprio e são oriundos da região. A proximidade com a Rodovia BR-277, que liga o Brasil à Argentina, também possibilita o fluxo de turistas estrangeiros. (FLORES, 2011).

As pessoas que visitam a Rota do Vinho (como é conhecido o percurso entre as vinícolas) têm conhecimento do local através da indicação de amigos, por intermédio das festas realizadas no município e pela proximidade com importantes rodovias, como a BR-153. (FLORES, 2011).

A falta de uma agência de turismo receptivo é um limitador para a comercialização do turismo local. Eventualmente os produtos são apresentados em feiras como a do pequeno produtor promovida pelo SEBRAE, porém não participam de eventos maiores. (FLORES, 2011).

A visitação é feita na sede das propriedades, com visitas às vinícolas e degustação de vinhos. (FLORES, 2011). Na maioria dos casos é apenas uma visita para compra de produtos que ocorre na sala de vendas. (FLORES, 2011). Devido à proximidade com importantes rodovias de ligação muitos viajantes em trânsito aproveitam a oportunidade para comprar vinho direto do produtor (FLORES, 2011).

A análise realizada pelo IBRAVIN sobre os denominados 4P's (ponto, preço, produto, promoção) em Bituruna revelou os seguintes resultados citados em Flores (2011): 
- Ponto - a distância de grandes centros e de aeroportos é um fator dificultante para o desenvolvimento do turismo na região.

- Preço - são adequados aos produtos oferecidos e ao perfil do consumidor.

- Produto - considerado bom podendo melhorar, principalmente no que se refere à infraestrutura de acesso, no desenvolvimento de mais atrativos. Os vinhos foram considerados regulares, porém estão em processo de melhoria. Os filhos dos produtores estão se especializando em enologia e atuando na empresa da família.

- Promoção - considerada regular uma vez que se limita a feiras regionais, vinculadas à produção. A atuação na internet é deficiente, uma vez que não existe um site que concentre as informações turísticas do município.

A análise dos fatores internos e externos revelou a seguinte realidade em relação ao enoturismo em Bituruna:

- Como pontos fortes se pode destacar a boa vontade política, o interesse da comunidade, os espaços com natureza bem preservada, a existência do "Empório do Produtor Rural" ponto de informações turísticas e de venda de produtos culturais e gastronômicos, a hospitalidade representada pela cordialidade típica da cultura italiana, o turismo religioso, as manifestações da cultura italiana presentes no dia a dia da comunidade e a diversidade de produtos à base de uva, tais como vinhos, sucos e geleias.

- Como pontos fracos se destacaram a existência de poucos atrativos turísticos nos arredores da cidade, a falta de profissionalização da atividade turística, falta de pessoal capacitado e que fale outros idiomas, a distância dos grandes centros, oferta hoteleira incipiente e precariedade das estradas de acesso às propriedades rurais vinícolas.

- Como oportunidades podem-se citar a localização, a proximidade com importantes rodovias de ligação, a motivação dos produtores, os eventos que poderão ser realizados no Empório do Produtor.

- E, por fim, as ameaças se caracterizam principalmente pelo fato de Bituruna ser uma cidade pouco conhecida em âmbito nacional e como produtora de vinhos, e pela produção limitada a vinhos de mesa. 


\section{A PRODUÇÃO DE VINHO E O TURISMO NA OPINIÃO DOS ENTREVISTADOS}

A entrevista realizada com produtores de vinho de Bituruna por meio de questionários enviados via internet aos quatro maiores produtores foi respondida pelos proprietários da Vinícola Bertoletti e da Vinícola Sanber, cujo resultado se descreve a seguir.

Quanto ao ano de inicio da produção a Vinícola Bertoletti surgiu em 1985 e a Vinícola Sanber em 2005, porém em ambas vinícolas ressaltam que a família sempre produziu vinho, desde a sua chegada à região por volta dos anos 1940.

Cada vinícola produz entre 70 e 80 mil litros de vinho por ano, sendo que, tradicionalmente, ambas produzem os vinhos de mesa e mais recentemente a Sanber vem investindo na produção de vinhos finos Cabernet Sauvignon e Merlot, como se pode observar no quadro abaixo.

\begin{tabular}{l|l|}
\hline \multicolumn{1}{|c|}{ VINÍCOLA BERTOLETTI } & \multicolumn{1}{c|}{ VINÍCOLA SANBER } \\
\hline Suco de uva & Vinho Branco de Mesa Seco Niágara \\
Vinho tinto fino seco Cabernet Sauvignon & Vinho Branco de Mesa Suave Niágara \\
Vinho de mesa branco seco Casca Dura & Vinho Branco de Mesa Seco Casca Dura \\
Vinho de mesa branco seco Niágara & Vinho Tinto de Mesa Seco Bordô \\
Vinho de mesa branco suave Niágara & Vinho Tinto de Mesa Suave Bordô \\
Vinho de mesa tinto seco Bordo & Vinho Tinto Fino Seco Cabernet Sauvignon \\
Vinho de mesa tinto suave Bordo & Vinho Tinto Fino Seco Merlot \\
\hline
\end{tabular}

Os dois entrevistados informaram que a tradição de produzir vinho foi herdada dos pais e estes de seus antepassados. Visando aprimorar as técnicas de produção, ambos declararam que os filhos estudaram enologia no Rio Grande do Sul e retornaram para melhorar a produção da família.

Além disso, que o SEBRAE/PR e o SENAR promoveram cursos de capacitação de boas práticas agrícolas para produção da uva e fabricação do vinho, do qual participaram nove produtores da fruta e quatro vinícolas. A enóloga Eliane Bertoletti, da vinícola Bertoletti, comentou que a participação nos cursos de capacitação os ensinou a fazer gestão de segurança, atendimento à legislação, ter controle de produção e, principalmente implantar sistemas de produção, que mostram a importância de fazer registros desde o plantio até a industrialização. 
As duas vinícolas recebem visitantes desde que foram abertas. A Bertoleti recebe ao mês em torno de 500 pessoas e a Sanber 100 pessoas, que vêm comprar vinho direto do produtor. Para melhor atender seus clientes, ambas fizeram adaptações em suas propriedades como, por exemplo, reorganização de horários, instalação de loja para venda dos seus produtos, abertura de acessos, sinalização, organização do layout da empresa, criação de site e folder para divulgação da vinícola e dos produtos que são comercializados mais fortemente em âmbito regional e em menor escala em âmbito nacional, no caso da Bertoletti.

Ambos os produtores concordaram existir uma forte relação entre a enocultura e o turismo e destacaram haver um grande interesse das pessoas em conhecer como os produtos são elaborados. O proprietário da Vinícola Sanber destacou que "o enoturismo é um dos ramos que mais está crescendo dentro do turismo nacional" e ressaltou que o consumidor de vinho em geral não busca apenas uma bebida, mas está também interessado na história do produto e do produtor.

Para atrair mais visitantes as vinícolas proporcionam outras atividades além da comercialização do vinho. A Bertoletti tem pescaria, trilha ecológica e passeio a cavalo. A Sanber conta com um casarão histórico e abre seus vinhedos para visitação. Sobre o assunto, um dos entrevistados (2013) declarou que "O consumidor de vinho em geral busca no vinho não apenas uma bebida, mas uma história, um cenário, algo a mais que o faça se sentir dentro de um ambiente agradável e se sentir privilegiado em provar de um produto que tem muito de quem o faz".

Vale observar que além da produção de vinho transmitida de geração em geração, os produtores mencionaram manter outros costumes herdados de seus antepassados italianos, tais como a culinária farta em massas, algumas palavras do dialeto italiano usados no dia a dia, a religiosidade e a receptividade calorosa, contribuindo para a formação de uma imagem turística autêntica ligada aos traços étnicos.

Flores (2012, p. 17) ressaltou estes aspectos no contexto nacional ao afirmar que:

O turismo do vinho no Brasil acompanha a história das imigrações. Sendo o vinho considerado pelos imigrantes italianos na serra gaúcha um alimento, trataram de cultivar a videira: tentaram viníferas italianas, francesas. Depois mudas americanas. Subiram morros, foram às margens de rios, aplicaram 
diferentes formas de cultivo, traçando paisagens exclusivas, como vinhedos delimitados com plátanos no interior da serra, únicos no mundo.

Tais características socioculturais podem servir de base para a criação de uma marca local com consequentes contribuições para o fortalecimento endógeno, tal como investigou Valduga (2012, p. 141), na região do Vale dos Vinhedos (Rio Grande do $\mathrm{Sul}$ ), onde "O fortalecimento endógeno ocorreu a partir do subsistema econômico, que impactou no subsistema social".

Com base nos dados coletados pela pesquisa empírica e análise dos diagnósticos sobre o enoturismo em Bituruna, cabe sintetizar que seu potencial turístico baseado na cultura étnica local, no capital intelectual de produção de vinhos, na comercialização deste produto, nos equipamentos turísticos presentes no município e infraestrutura pública disponível, indicou que o turismo poderia trazer benefícios para o desenvolvimento local.

Os fatores limitadores para o desenvolvimento do turismo como a precariedade das estradas de acesso às vinícolas, a oferta hoteleira incipiente e a falta de uma agência de receptivo local deveriam receber, respectivamente, investimentos públicos e interesse da iniciativa privada em fomentar novos negócios, na medida em que o enoturismo gere demanda compatível para o crescimento do setor.

\section{CONCLUSÕES}

A presente pesquisa comprovou o potencial do município para o enoturismo, tanto a partir da produção vitivinícola e estrutura disponível nas propriedades, quanto pela organização entre os empreendedores, apoio do poder público local e assessoria de outras entidades.

Apesar de a produção de vinho ainda ser considerada artesanal e limitada ao vinho de mesa, um dos grandes produtores locais começou a investir na fabricação de vinhos finos, indicando um caminho a ser seguido por outros.

Outro fator positivo é o constante aprimoramento da qualidade dos vinhos por meio da realização de cursos de enologia pelos membros das famílias produtoras, 
principalmente entre as novas gerações que estão assumindo os negócios dos pais e criando também novas empresas, como é o caso da Sanber.

Vale também ressaltar a experiência positiva dos entrevistados com atrativos que podem compor a oferta do enoturismo de forma complementar, contribuindo para o seu fortalecimento, tais como locais para pesca, trilhas ecológicas, passeios a cavalo, patrimônio arquitetônico e paisagem rural.

Sendo assim, acredita-se que a produção de vinhos aliada aos aspectos da cultura étnica dos moradores mostra-se promissora como tema principal da oferta turística de Bituruna, possibilitando a consolidação do enoturismo como propulsor de desenvolvimento local, a exemplo de outras regiões do Sul do Brasil.

\section{REFERÊNCIAS}

BITURUNA. PREFEITURA MUNICIPAL. Pontos turísticos: vinícolas. Disponível em: <http://www.bituruna.pr.gov.br/turismo-lista.php>. Acesso em: 16/09/2013.

História. Disponível em:

<http://www.bituruna.pr.gov.br/base.php?id=historia>. Acesso em: 16/09/2013.

FLORES, M. A. D.; FLORES, A. Diagnóstico do enoturismo brasileiro: um mercado de oportunidades. SEBRAE: Brasília, DF; IBRAVIN: Bento Gonçalves, RS, 2012.

Diagnóstico de realidade do enoturismo brasileiro: um mercado de oportunidades. SEBRAE, IBRAVIN: Porto Alegre, 2011.

HALL, C. M.; SHARPLES, L; CAMBOURNE, B.; MACIONIS, N. (Org.). Wine tourism around the world: development, management and markets. Oxford: Elsevier, 2004.

MITCHELL, R.; HALL, C. M. Wine tourism research: the state of play. Tourism Review International, v. 9, n. 4, 2006. p. 307-332.

NITSCHE, L. B. Relatório de pesquisa do projeto Turismo e desenvolvimento rural no Brasil: março de 2014. Departamento de Turismo, UFPR, 2014.

SOUZA, S. A. de P. Pressupostos para a educação turística em municípios: uma alternativa para o planejamento do turismo com base local no Município de Bituruna, PR (Dissertação de Mestrado) Programa de Pós-Graduação strictu sensu em Turismo e Hotelaria. Universidade do Vale do Itajaí. Balneário Camboriú, 2008. 
TERRA DOS PINHEIRAIS. Bituruna. Disponível em: <http://www.terradospinheirais.tur.br/municipios.php>. Acesso em: 16/09/2013.

VALDUGA, V. O desenvolvimento do enoturismo no Vale dos Vinhedos (RS/Brasil). Revista de Cultura e Turismo (Cultur). Ano 6, n. 2, junho, 2012. p. 127-143. Disponível em: <www.uesc.br/revistas/culturaeturismo>. Acesso em: 10/04/2014.

ZANINI, T. V.; ROCHA, J. M. O Enoturismo no Brasil: um estudo comparativo entre as regiões vinícolas do Vale dos Vinhedos (RS) e do Vale do São Francisco (BA/PE). Revista Eletrônica Turismo em Análise, v. 21, n. 1, abril 2010. p. 68-88. Disponível em: <http://turismoemanalise.org.br/turismoemanalise/article/view/72/72>. Acesso em: 27/03/2014.

Recebido em: 15-05-2014.

Aprovado em: 13-06-2014. 